\title{
The Math Alliance and Its Roots in the African American Community
}

\author{
David Goldberg and Phil Kutzko
}

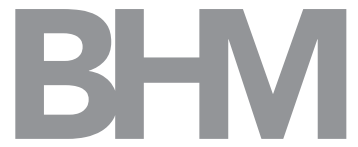

The Math Alliance, a national community of math sciences faculty committed to increasing the number of doctoral degrees awarded in those fields to underrepresented minority students, began in 1995 at the math department at the University of Iowa. In 2016 it moved to the College of Science at Purdue University. Math Alliance Executive Director David Goldberg and Math Alliance Director Phil Kutzko sat down to discuss the history of the Alliance and its relationship to the African American community.

EDITOR'S NOTE. In 2017 the Math Alliance won the AMS Award for Mathematics Programs That Make a Difference. ${ }^{1}$ In 2014 Philip Kutzko received the AMS Award for Distinguished Public Service. ${ }^{2}$

Goldberg: When you and your colleagues began your initiative at the University of Iowa, I don't think many folks would have bet on its success. And yet, twenty-two years later, thirty-four minority students have received $\mathrm{PhDs}$ from your department, including nine African Americans, and the Alliance has exceeded all expectations. How can you explain this?

Kutzko: It is actually hard to explain. If you'd have told me back then that a largely white department at a predominantly white university in a definitively white state

David Goldberg is executive director of the Math Alliance. His email address is goldbergapurdue. edu.

Phil Kutzko is director of the Math Alliance. His email address is Phi1ip-kutzko@uiowa.edu.

${ }^{1}$ See www.ams.org/publications/journals/notices/201705/ rnoti-p476.pdf.

${ }^{2}$ See www . ams . org/notices/201404/rnoti-p409.pdf.

For permission to reprint this article, please contact:

reprint-permission@ams .org.

DOI: http://dx.doi.org/10.1090/noti1635

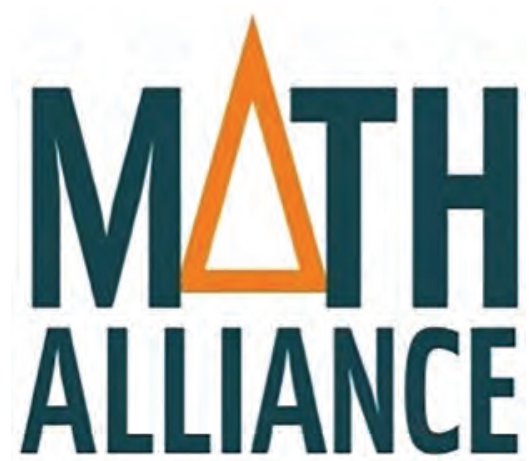

would have this kind of success, I would have wondered if we were living in the same country. And yet, if we are going to institutionalize this success we must try to understand the factors that led to it. One factor was the group of faculty at Iowa who started this initiative. We were about fifteen percent of the faculty, but we were all tenured, and most of us had good research credentials. We counted among our group our chair and our director of graduate studies. So those faculty in our department who were skeptical of what we were trying to do-and there were many-were inclined to let us give it a try. A second factor is that we all mentored. In fact, our department had always had a culture of mentoring, although I don't think we called it that or talked about it much before our initiative. These two factors, a critical mass of faculty and a culture of mentoring, formed the basis of our Alliance Graduate Program Groups.

Goldberg: Our department at Purdue was watching the developments at Iowa with great interest. There was a small group of Purdue math faculty who were interested in trying to change the demographics of the graduate student population and, more importantly, in trying to improve the experience for underrepresented minority students in our program. We adopted some of the mentoring structures from Iowa, and several faculty engaged in a program to recruit more thoroughly from minority-serving institutions.

Kutzko: How did it go?

Goldberg: The early results were mixed at best. Our department received its first GAANN grant in 2000 and was successful in attracting six underrepresented minority students to the program. Two of these students received PhDs, but the faculty mentors were not always successful in protecting them from painful experiences. Our colleagues at minority-serving institutions who had entrusted 


\section{"The Alliance has exceeded all expectations."}

their students to us were disappointed. Like many well-meaning departments, we found ourselves more part of the problem than the solution.

Kutzko: I always worried that that might happen with us. We had heard of so many departments who had begun to question whether the benefits of sending students to graduate schools at departments like ours was worth the risk.

Goldberg: How did you avoid this situation?

Kutzko: A lot of it was dumb luck! One of our original group, Herb Hethcote, was a colleague of Carlos Castillo-Chavez, and Carlos began to send us alumni of his MTBI program. Carlos was, even then, an important leader in the work we do, and he was very clear in his expectations of us. Most of our early PhDs were recommended to us by Carlos; eleven of our first twelve PhDs were Latinos.

Goldberg: It is interesting that, since that time, about thirty-five percent of your minority PhDs have been African American. Did you do something intentional to increase your numbers of African Americans?

Kutzko: Yes, we did, and this led to our original Alliance. The story is a good one. Sometime in 2001, Gene Madison $^{3}$ and I were at a social occasion in Iowa City and we were discussing, over a game of Bid Whist, ${ }^{4}$ the fact that our minority grad students up to that point had been overwhelmingly Latino. It turned out that another player at our table had gone to Florida Agricultural and Mechanical University (FAMU) and had a sister who was friends with Roselyn Williams, the FAMU math department chair. Gene and I went down to FAMU about two weeks later. We agreed that we would form an Alliance-the Alliance for the Production of African American PhDs in the Mathematical Sciences, that Roselyn would recruit representatives of three other Historically Black Colleges and Universities (HBCUs), that Gene and I would reach out to the math sciences departments at the three Iowa State Regents universities, and that we would meet again. We returned to FAMU with seven or eight faculty in the math sciences at all three of the Iowa schools and met there with faculty from our new HBCU partners: Benedict College, Alabama A\&M University, and Jackson State University, in addition to FAMU. We came up with a detailed plan and drafted a proposal to the Division of Math Sciences (DMS) at NSF.

\footnotetext{
${ }^{3}$ Eugene Madison, now retired, was professor of mathematics at the University of Iowa and among the first African Americans to hold such a post. He played a critical role in the UI math department's graduate minority initiative.

${ }^{4}$ For more on this card game popular among African Americans, see the NPR "...Story of Bid Whist" at www.npr.org/templates/ story/story.php?storyId=5069913.
}

Goldberg: I am assuming you were funded.

Kutzko: Not at first! Our initial proposal was rejected due to some strongly negative comments about HBCUs on the part of one of the reviewers. However, we were very fortunate that Philippe Tondeur, professor of mathematics at the University of Illinois, was the director of DMS. Tondeur encouraged us to apply again and to make the case for HBCUs. We were funded on our second try.

Goldberg: If I am remembering right, both mathematics and statistics were represented in the meeting at FAMU.

Kutzko: Yes, that is right. In fact, the Alliance has served all of the mathematical sciences from its very beginning. Dean Isaacson, who was chair of the Iowa State University statistics department, was a leader in the Alliance until his retirement. Kathryn Chaloner (Figure 1), chair of biostatistics at the University of Iowa until her untimely death, headed our Alliance statistics initiative. The biostatistics department provided the Alliance with office space and staff support until its move to Purdue. Leslie McClure, chair of biostatistics at Drexel University, has taken over Kathryn's responsibilities; she is our associate director for statistics.

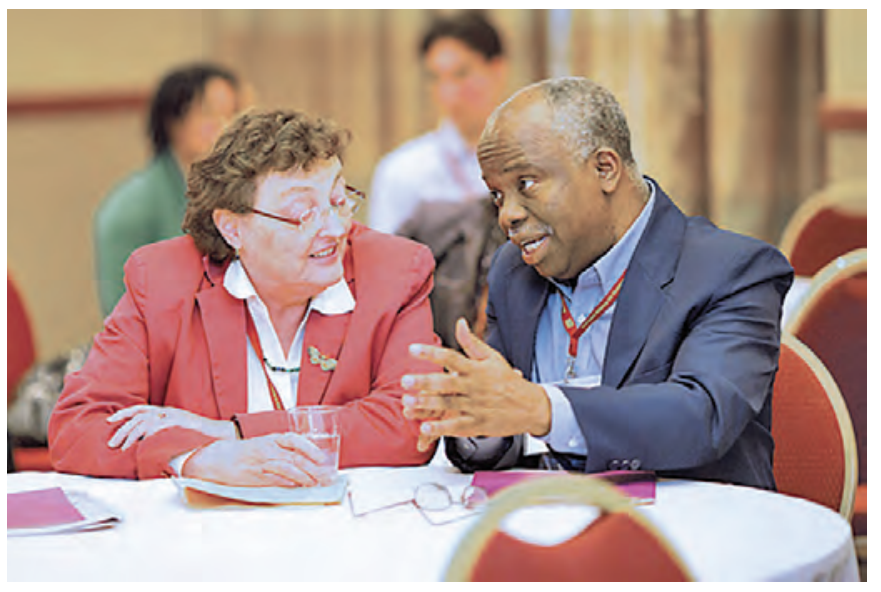

Figure 1. Kathyrn Chaloner, founder of the Alliance Statistics Initiative, talks with Professor Joe Omojola.

Goldberg: How did the new Alliance go?

Kutzko: We had mixed success. Quite a few students participated in the new Alliance each year, but not all of them had the background to enter our doctoral programs. Several of them entered the master's program at the University of Northern Iowa, but some of these students chose to enter doctoral programs in non-math sciences fields or they dropped out altogether. There were some real successes though, and one of them, Reggie McGee, received his $\mathrm{PhD}$ at Purdue.

Goldberg: Reggie was a really important figure in the transformation of our department, and we were very fortunate that he chose to come to Purdue. I first met Reggie when he was in the Alliance summer program at Iowa, and I happened to be there working with you on a research paper. Then a couple of years later he visited Purdue through the HBI Visitation Program, and we were 

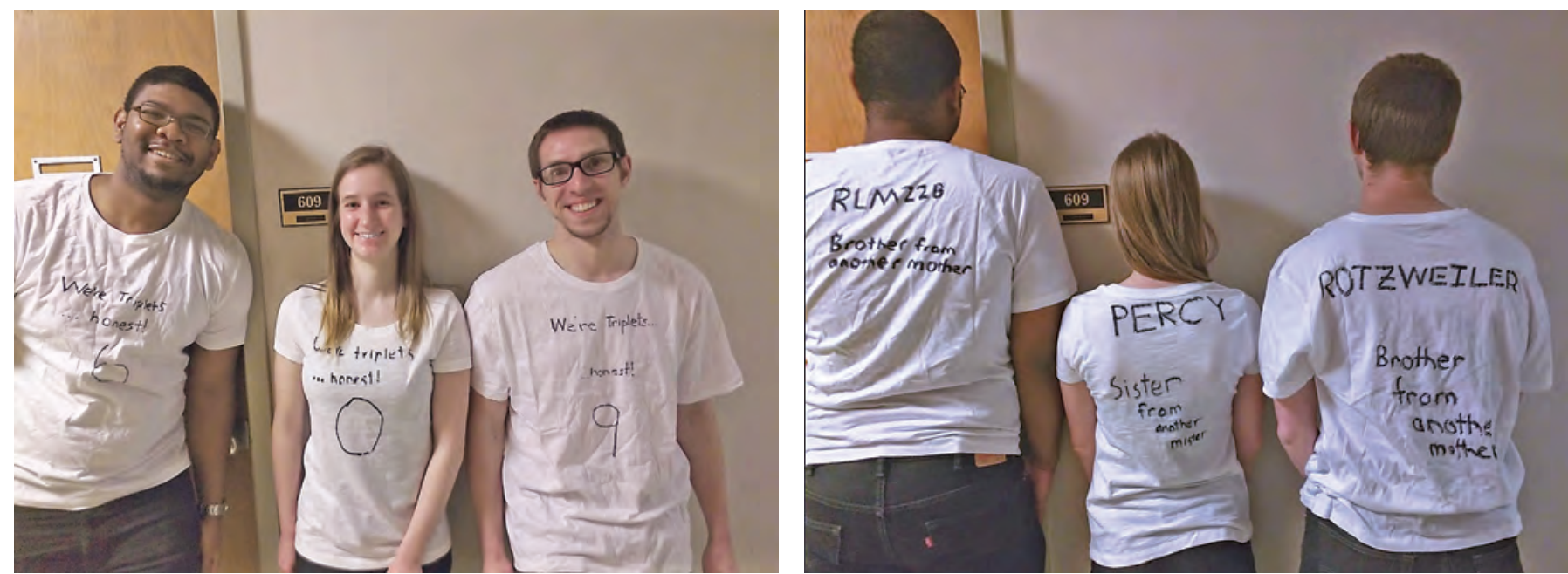

Figure 2. Reggie McGee started a grad student Twin Day and posed with his office mates Sarah Percival and Kevin Rotz as triplets.

successful in recruiting him to our department. If I remember right, you called me to say we should take him. He forged a community for himself within the department right away, and was quite a cheerleader for people succeeding and working together, for instance on preparing for qualifying exams. He also connected with the wider campus community, and he was very active in the Purdue Black Graduate Student Association. He also became a graduate representative in our department; he represented the grad students to the grad chair (me), and he had a lot of good ideas about making our department a better place. He and his fellow grad reps had a whole series of events and competitions for the week before final exams. One day was Twin Day, where you had to find someone and dress up as twins. Reggie and his office mates actually went as triplets (Figure 2), and it was pretty hilarious. He also was very outspoken about certain conditions for the graduate students. This helped set a tone for how dialog between the faculty and grad students about our climate could move forward.

Reggie worked with Greg Buzzard (now head of our department) on mathematical biology. With Greg, Reggie really blossomed as a researcher. His thesis studied something about modeling certain signal processes between diseased cells. He finished in six years, and then took a postdoc position at MBI.

Kutzko: You were fortunate in the make-up of your department during your transition from a more traditional department to one of our strongest Doctoral Program Groups (DPGs).

Goldberg: Yes. Rodrigo Bañuelos and Johnny Brown had already been in our department for a long time, and both have been stalwarts in working for diversity in our department and across campus. They have been great role models and mentors not only to minority students but also to majority students and junior faculty. At one point Rodrigo was head and Johnny was associate head, and one external review commented that to their knowledge it was the first time a Group I department had had underrepresented minority faculty in both of its top two leadership positions. We're also lucky that Greg Buzzard is now our head; he has been very proactive in diversity issues, and supportive of initiatives to improve the climate. $\mathrm{He}$ was a big part of making the idea that the Alliance could come to Purdue a reality. We had the challenging task of replacing Billie Townsend (Figure 3) as program manager and were lucky to hire Rebecca Lank. And, of course, neither the transition you asked about nor the Alliance's move to Purdue could have occurred without Edray Goins! Edray joined our faculty in 2004 and, besides making an immediate contribution to our research effort, went about doing a lot of important things which hadn't been done before, such as undergraduate research. In addition to his work at Purdue, he has taken on several national roles, including president of NAM. When the Alliance moved to Purdue, we were really fortunate that Edray agreed to be associate director. He provided new ideas, strengthened ties with the HBCU community, and played a crucial role

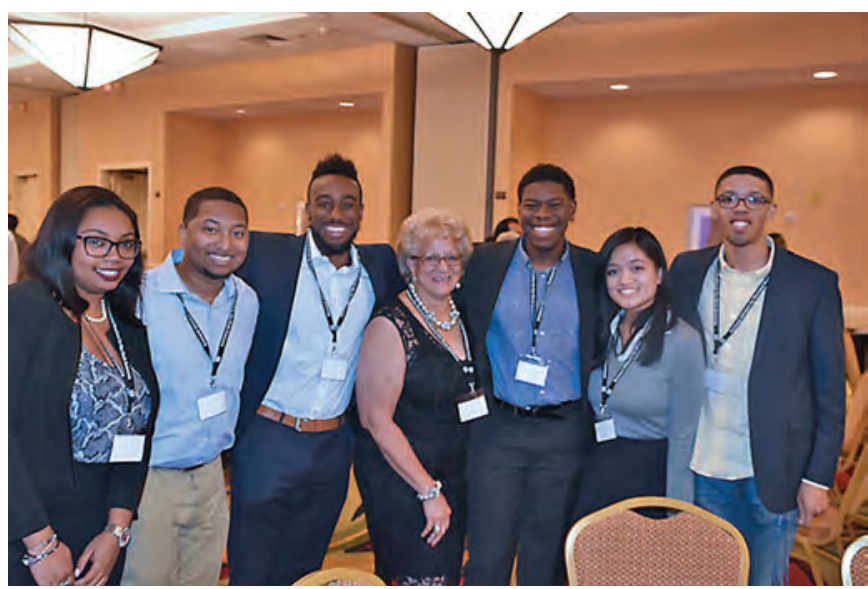

Figure 3. Billie Townsend (center), retired Alliance program manager, and some Alliance scholars at the 2016 Field of Dreams Conference. 
in all developments and decisions. Edray has decided to step away from his work with the Alliance, and he'll be joining the faculty at Pomona College in the fall of 2018.

Kutzko: The Alliance has come a long way from its origins as a partnership between four HBCUs and the three Iowa Regents Universities. As our new executive director, how does it look to you now?

Goldberg: The Alliance has changed in certain fundamental ways since 2007 , when the decision was made to transform the original partnership into a national community. And it changed again in 2016 when we evolved from an NSF-funded project to an independent organization, ${ }^{5}$ an organization with the potential to transform the culture and the demographics of our math sciences professions. But what will never change will be our commitment to the African American community.

- We have strong ties with NAM and look forward to working with them in the coming years.

- We have built a strong tie with CAARMS and with its director, Bill Massey, and will work closely with Bill and with the CAARMS network as we continue to build regional alliances in the Northeast.

- We have close relationships with the faculty of several HBCUs including, of course, our original partners Jackson St. and FAMU, but also Southern University at New Orleans, Xavier University of Louisiana, Morehouse College, Spelman College, and Texas Southern University. These and other HBCUs are enrolling an increasing number of their Alliance Scholars each year into our Facilitated Graduate Admissions Process (F-GAP) program and, with the help of F-GAP, more and more of these African American Alliance Scholars are entering graduate programs in the mathematical sciences. (See Figure 4.)

Our numbers so far are good. Over the last two years, twenty-one minority students who started out as Alliance Scholars earned a doctoral degree in a math science. Of these students, almost half (nine) were African Americans. And we have every reason for optimism when we look at our DPGs. In fact, over the past ten years, at least 80 African Americans have been awarded PhDs by these departments, about thirty-eight percent of all doctoral degrees awarded to African Americans in the math sciences during this time.

Kutzko: Our colleague, Leslie Hogben, over at Iowa State University has informed me that their math department will be awarding PhDs to four African American mathematicians in spring and summer, 2018, a fitting achievement for original Alliance. ${ }^{6}$ one of the founding departments of the

Goldberg: Any final thoughts?

Kutzko: I guess we both feel humbled by these accomplishments. I grew up at a time when schools were segregated and I can remember seeing the separate drinking fountains. I remember the deep sense of injustice my parents felt about this and how strongly they expressed it. And I remember your dad and mom and that they had devoted their lives to making the kind of change that we have had the honor to be a part of through the Alliance.

I never thought that, through this work, I would have the opportunity to meet some real heroes, like Bob Moses and our friend Donald Cole, who has played such a critical leadership role in our Alliance community. I never thought I would live to see Barack Obama become President of the United States, and I certainly never imagined that I would
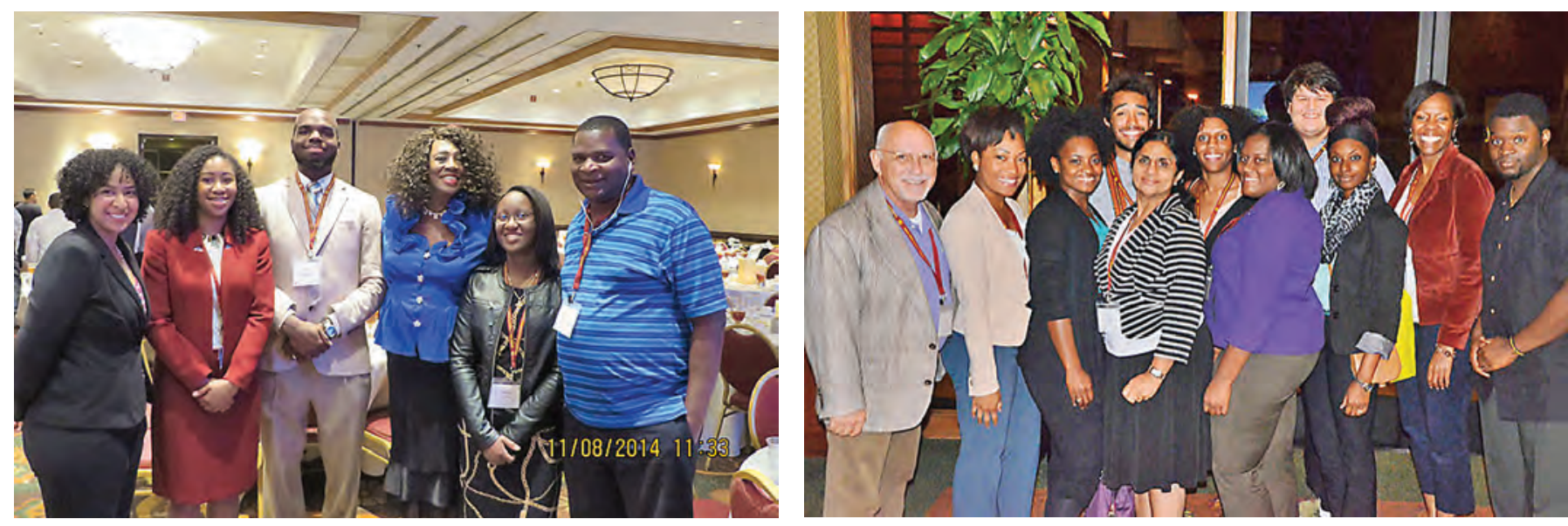

Figure 4. The Alliance has close relationships with several HBCUs. Left: Texas Southern students, alums, and faculty at the 2014 Field of Dreams Conference: Valerie Tolbert, Marquesha Forman, Aqeeb Sabree, Joan Evans, Franchell Davidson, Roderick Holmes. Right: Professors Lester Jones (left) and Sindhu Unnithan (center) and the Xavier University of Louisiana contingent at the 2014 Field of Dreams Conference.

\footnotetext{
${ }^{5}$ Information about the history and governance of the Alliance as well as complete data may be found at mathal1iance.org/ about-the-math-a11iance/.
}

${ }^{6}$ In 2015, the mathematics department at Iowa State won the AMS Award for an Exemplary Program or Achievement in a Mathematics Department; see www . ams . org/notices/201505/ rnoti-p544.pdf 


\section{BLACK HISTORY MONTH}

get a chance to meet him. But, most of all, I never imagined that there were so many faculty in our professions who felt just as you and I do, who remember how things were and who will give their time and their heart to making sure that our professions provide a welcoming and supportive environment to anyone who feels the unlikely passion that we feel for what everybody else sees as hopelessly abstract.

The Alliance has broken new ground, but there were big steps in this direction before. Among others, we should never forget Raymond Johnson, whose accomplishments at the University of Maryland taught us what might be possible at our Iowa schools and at Purdue. But, again and again, a shift of emphasis in a department or a change of administration at a university or even a couple of retirements have led to a loss of momentum and the process must be begun again. So I would like to end with a plea: This time, let's make it permanent! Let us work together to institutionalize what the Alliance has accomplished in our colleges, and universities, and professional organizations.

EDITOR'S NOTE. Also see the September 2016 Notices interview with Goldberg and the December 2017 AMS inclusion/exclusion blog post on the Math Alliance at http://bit.7y/2ABtLRI.

\section{Photo Credits}

Figure 1 by Matt Le.

Figure 2 by Rebecca Lank.

Figure 3 by Donald Cole.

Figure 4 by Billie Townsend.

Figure 5 by Donald Cole.

Photo of Phil Kutzko and David Goldberg by Donald Cole.

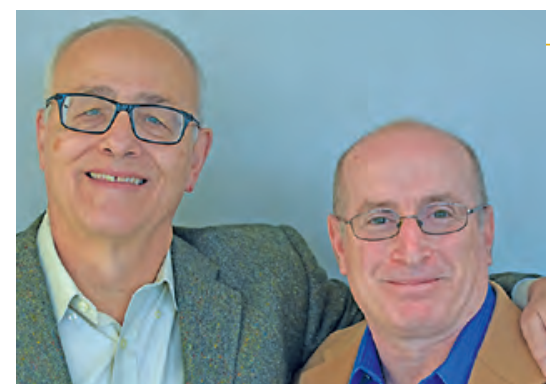

Phil Kutzko and David Goldberg
ABOUT THE

AUTHORS

Phil Kutzko and David Goldberg at the 2017 Field of Dreams Conference. Phil still dreams of beating David at handball, some day. 